\title{
Article \\ Experimental Investigation of Particle Size Degradation and Plugging Efficiency of Three Granular Lost Circulation Materials
}

\author{
Saleh A. Alhaidari ${ }^{1}$ and Sulaiman A. Alarifi ${ }^{2, *(D)}$ \\ 1 Saudi Aramco, Dhahran 31311, Saudi Arabia; saleh.haidary@aramco.com \\ 2 Department of Petroleum Engineering, King Fahd University of Petroleum \& Minerals, \\ Dhahran 31261, Saudi Arabia \\ * Correspondence: salarifi@kfupm.edu.sa; Tel.: +966-13860-8716
}

Citation: Alhaidari, S.A.; Alarifi, S.A. Experimental Investigation of Particle Size Degradation and Plugging Efficiency of Three Granular Lost Circulation Materials. Appl. Sci. 2021, 11, 9061. https://doi.org/10.3390/ app11199061

Academic Editor: David

Charles Barton

Received: 31 August 2021

Accepted: 24 September 2021

Published: 28 September 2021

Publisher's Note: MDPI stays neutral with regard to jurisdictional claims in published maps and institutional affiliations.

Copyright: (c) 2021 by the authors. Licensee MDPI, Basel, Switzerland. This article is an open access article distributed under the terms and conditions of the Creative Commons Attribution (CC BY) license (https:// creativecommons.org/licenses/by/ $4.0 /)$.

\begin{abstract}
This work delineates a comprehensive study of one of the main problems that contributes towards nonproductive time (NPT) in a drilling operation, which is lost circulation. The focus of this study was to investigate the performance of walnut, graphite, and marble, which are three widely used and industry-available granular lost circulation materials (LCMs). Additionally, the study aimed to establish a particle size selection guideline for better operational performance and plugging efficiency. Four water-based carrier fluid systems (water-bentonite mix, water-polymer mix, and two polymer-salt systems) were tested with the LCMs in this study. Dry and wet particle size degradation studies were conducted on all the LCMs with the different carrier fluid systems to study their compatibility and efficiency. The effect of the carrier fluid type was proven to be significant only on marble particles size degradation; walnut and graphite were not affected by the carrier fluids and showed consistent size degradation performance with all fluids. The results of this work led to newly developed particle size selection guidelines to enhance plugging efficiency-guidelines that are custom-made for each material by taking into consideration the rate of the degradation and type of material and by correlating the findings with fracture width. Applying this method of investigation to the current lost circulation management practice can help resolve many lost circulation incidents by effectively and efficiently selecting the appropriate LCM.
\end{abstract}

Keywords: lost circulation materials; particle size degradation; plugging efficiency

\section{Introduction}

During drilling for oil and gas, drilling fluid plays an essential role in the success of the drilling operation. It is used for several reasons, including cooling the drilling bit, carrying drilled cuttings to the surface, reducing friction, and maintaining borehole integrity. Using drilling fluid with the appropriate properties for every condition and for the different zones drilled through is critical [1]. Research is continuously conducted to improve the performance of drilling fluids. Several additives can be added to the drilling fluid to enhance its performance [2]. Lost circulation materials (LCMs) are drilling fluid additives designed to ensure that the fluid that is circulated down the hole is returned to the surface rather than flowing into the formation drilled [3].

Lost circulation is the uncontrolled flow of operational (drilling) fluids into the formation due to several reasons caused mainly by improper fluid properties or drilling conditions. For decades, lost circulation events have been managed in a multitude of ways and without a consistent methodology or approach. Lost circulation is a major problem in the drilling industry, especially in depleted and mature fields. Lost circulation costs the industry around USD 2 to 4 billion annually [4]. Tremendous efforts have been made by many companies and researchers around the world to mitigate lost circulation problems; yet, lost circulation remains an ongoing challenge. Current lost circulation management 
techniques, which include the "ready-made" pill designed by service companies, cement plugs, and non-formation-specific formulations, have reached the current limit of their effectiveness, especially when it comes to complicated conditions such as conductive fractures as well as weak and depleted formations. LCM manufacturers claim that these new materials will solve the issue, and yet, it is difficult to determine which new materials are appropriate for a given situation. Hence, lost circulation problems still exist.

Oil and gas companies will often face fluid loss during drilling operations. Many drilling hazards could be the direct result of loss circulation, such as hole collapse, stuck pipe, and blowouts [5]. The main cause of fluid losses is drilling through zones with natural fractures, cavernous zones, or a high permeability matrix [6-8]. To cure mud losses, many operators' first approach is the addition of LCMs in the drilling fluid. The use of the LCM is mainly intended to cure existing losses, but using LCM as a preventive practice has been documented [9]. Research and development efforts on the lost circulation problems must be aligned with many factors, such as, drilling fluid selection, size degradation of the LCM upon shearing, and finally implementing ways to strengthen the fracture gradient of the formation.

The particle size distribution of the LCM is the only widely used method for designing and planning the sealing or plugging mechanism to mitigate a lost circulation event. One of the criteria for selecting which material to use is the correlation between the particle size and the fracture width or pore size. This criterion assumes that both the anticipated fractures/pore sizes and the selected LCM particle size distribution (PSD) will be maintained when the material reaches the thief zone or fracture downhole.

Size degradation is due to mechanical shearing or a dynamic force that acts on the particles of the LCM by the mud pumps, drill string, wellbore annulus, and bit nozzles [10]. Many authors in the literature have spent a lot of time and effort studying size degradation. Grant et al. (2016) examined the size degradation of two LCMs (graphite and marble) using a flow loop [11]. The study revealed that the graphite showed a 16\% PSD reduction in size, while ground marble recorded a PSD size reduction of $35 \%$.

Scott et al. (2012) conducted a size degradation lab experiment on three materials: walnut hulls, graphite, and ground marble. The shearing speed was 7000 revolutions per minute (RPM) for intervals of 5 and $15 \mathrm{~min}$. Their results revealed that the large particles were more prone to degradation than the finer particles. Their results also demonstrated that walnut and graphite show a lower percentage of degradation and were able to sustain the high shear. Ground marble degraded the most and thus was not recommended for wellbore strengthening or lost circulation applications [12]. The study reported in this paper agrees with the conclusions of Scott et al. but takes the study beyond the basic degradation study.

Each material behaves differently under high shear because of the different physical and chemical properties of these materials [13]. To fully understand the underlying science requires an analysis of the type of fluid used and the impact of size degradation on LCM plugging efficiency. There is a need for further investigation of the effect of the material size degradation due to shearing with regard to the plugging efficiency. There is clearly a wide gap between understanding the impact of degradation and the ability of the LCM to adequately perform fracture sealing [14].

Many guidelines have been introduced in the literature for addressing the selection of the optimum bridging mechanism. These various guidelines are used in the industry to choose the particle size of bridging materials that can form an efficient external filter cake and minimize formation damage. Table 1 summarizes several of the current selection guidelines. These guidelines correlate fracture width with the size of LCM to achieve the paramount sealing of the fracture. The first criterion states that the median particle size $\left(D_{50}\right)$ must be approximately equal to or greater than one-third of the average pore throat size. A different criterion introduced by Abrams (1977) states that the volume of the LCM must be $5 \%$ or more of the total solids volume in the solution to attain the optimum bridging [15]. 
Table 1. Current LCM particle size selection guidelines for plugging efficiency.

\begin{tabular}{cc}
\hline Model & Criteria \\
\hline Abrams (1977) [15] & $D_{50} \geq 1 / 3$ the formation average pore size \\
Smith et al. (1996) [16] & The volume of the LCM must be $5 \%$ or more of the total solids volume \\
& $D_{90}=$ the formation average pore size \\
$D_{90}=$ the largest pore throat size \\
$D_{75}<2 / 3$ largest pore throat size \\
Vickers et al. (2006) & $D_{50} \geq 1 / 3$ the formation average pore size \\
[17] & $D_{25}=1 / 7$ the mean pore throat \\
& $D_{10}>$ the smallest pore in the formation \\
Whitfill (2008) [18] & $D_{50}=$ fracture width \\
\hline
\end{tabular}

Smith et al. developed a criterion that is based on a lab-scale and field application. In their criterion, the $D_{90}$ of material must be equal to the pore size to reduce the fluid invasion [16]. Vickers et al. produced different criteria for bridging the pore size and suggested that the five D-values must be considered in the selection criteria. $\mathrm{D}_{10}$ has to be higher than the smallest pore in the formation, $\mathrm{D}_{25}$ must be equal to one-seventh of the average pore size, $D_{50}$ must be equal to or larger than one-third of the formation pore throat size, $\mathrm{D}_{75}$ must be less than two-thirds the pore throat size, and $\mathrm{D}_{90}$ should be equal to the largest pore throat size [17]. Furthermore, Whitfill presented a bridging guideline that considers the fracture width being equal to the $\mathrm{D}_{50}$ of the PSD of the bridging materials [18].

The objective of all these guidelines is the same-to plug the fracture or pore throat that leads to managing and resolving the lost circulation problem. The essential factor in developing these guidelines was the dry particle size distribution of the material without considering the impact of the drilling fluid, any possible size degradation, and the type of the material.

This study sheds light on the degradation rate of LCMs in different fluids and shows degradation effects on plugging different fracture width sizes. The traditional particle size selection guidelines are in need of an enhancement, and hence, by taking into consideration the rate of the degradation, type of material, and correlating those findings with the fracture width size, this study developed a new particle size selection guideline that is custom-made for each material. These guidelines demonstrate material performance based on the dry and wet particle size distribution (PSD) and examine the impact of material choice and fluid interaction when plugging a given fracture width size. Furthermore, this work shows the development process of the experimentally based particle size selection guidelines for optimizing a material's plugging capability.

The first phase of this study was the development of four carrier fluid systems for the selected LCMs. This phase was conducted to deeply understand the impact of different types of fluid systems with a wide range of fluid properties and the effect of those fluids on LCM performance. The second phase of this work was studying and analyzing LCMs and fluids interaction. The analysis of this phase included intensive experimental lab work on each material, including a size degradation study. The final phase was a state-of-the-art new experimental design for measuring LCM performance and validating the current particle size selection criteria. The overall impact of this research project is showing that applying this method of investigation to a current lost circulation management practice can help resolve many lost circulation incidents by effectively and efficiently applying the right LCM to each specific situation.

\section{Material and Methods}

\subsection{Materials}

\subsubsection{Carrier Fluids Design}

The carrier fluids design carried out in this study was an in-depth analysis of the four water-based fluid systems: water-bentonite mix (clay system), water-polymer mix (polymer system), and polymer-salt systems using $\mathrm{NaCl}$ and $\mathrm{CaCl}_{2}$ salts. The polymer 
used was xanthan gum, which is a hydrocolloid polymer. For the first polymer-salt system, $15 \mathrm{wt} \% \mathrm{NaCl}$ was added, while for the second polymer salt system, $20 \mathrm{wt} \% \mathrm{CaCl}_{2}$ was added.

As noted in the literature, fluid viscosity is an essential factor in managing the rate of fluid loss into the formation. This study also added other factors, such as examining the different viscosity sources (e.g., clay and polymers) in the fluid designs and thoroughly analyzing the effect of the viscosity, in addition to the different viscosifying agents. Another factor was to examine the impact of salt on the material performance, particularly the particles' size degradation. The carrier fluid formulations used are shown in Table 2, and their properties (i.e., $\mathrm{pH}$, plastic viscosity, yield point, and API fluid loss) were measured and are shown in Table 3.

Table 2. Carrier fluid formulations.

\begin{tabular}{ccccc}
\hline \multirow{2}{*}{ Additives } & Clay System & Polymer System & NaCl-Polymer & $\mathrm{CaCl}_{2}$-Polymer \\
\cline { 2 - 5 } & \multicolumn{4}{c}{ Quantity } \\
\hline${\text { Water, } \mathrm{m}^{3}}^{3}$ & 0.154 & 0.157 & 0.148 & 0.138 \\
Bentonite, $\mathrm{kg}$ & 9.07 & 0 & 0 & 0 \\
Polymer, $\mathrm{kg}$ & 0 & 0.68 & 0.68 & 0.68 \\
$\mathrm{Starch}, \mathrm{kg}$ & 2.72 & 2.72 & 2.72 & 2.72 \\
$\mathrm{NaCl}, \mathrm{kg}$ & 0 & 0 & 26.31 & 0 \\
$\mathrm{CaCl}_{2}, \mathrm{~kg}$ & 0 & 0 & 0 & 47.63 \\
\hline
\end{tabular}

Table 3. Properties of the four drilling fluids.

\begin{tabular}{|c|c|c|c|c|}
\hline Drilling Fluids Formulations & $\mathrm{pH}$ & $\begin{array}{l}\text { Plastic Viscosity } \\
\text { (cP) }\end{array}$ & $\begin{array}{l}\text { Yield Point } \\
\left(\mathrm{lb} / 100 \mathrm{ft}^{2}\right)\end{array}$ & $\begin{array}{l}\text { API Fluid } \\
\text { Loss (mL) }\end{array}$ \\
\hline Clay system & 11 & 17 & 26 & 4.4 \\
\hline Polymer system & 10 & 8 & 20 & 8.8 \\
\hline Polymer system-15 $\mathrm{wt} \% \mathrm{NaCl}$ & 10 & 15 & 20 & 8.8 \\
\hline Polymer system-20 $\mathrm{wt} \% \mathrm{CaCl}_{2}$ & 9 & 25 & 20 & 6.7 \\
\hline
\end{tabular}

\subsubsection{Granular Lost Circulation Materials (LCMs)}

This study investigated three members of the granular group of LCMs, which are walnut, graphite, and marble. Walnut, graphite, and marble are common granular materials that are highly rigid materials and have been used for decades in drilling fluids and lost circulation treatments. Each of these raw materials is sold under a variety of trade names by many companies.

The main characteristics of granular material are their size and shape. Granular materials can form a seal inside the pore of the formation because of their wide particle size distribution and shape [19]. Their particles show a high level of rigidity and crushing resistance; therefore, they are also used in wellbore strengthen applications $[7,20]$. The design of the particle size distribution of granular materials must include small and large particle sizes. Large particles form a bridge across the fracture, while the small particles fill the space between the large particles. Thus, a wide size distribution is more effective than a narrow one.

\subsection{Methodology}

\subsubsection{Wet Sieve Testing for Size Degradation}

The selected materials (walnut, graphite, and marble) were mixed for two-time intervals with the four selected fluids (water-bentonite mix, water-polymer mix, polymer-salt system using $\mathrm{NaCl}$ salt, and polymer-salt system using $\mathrm{CaCl}_{2}$ salt). All fluids systems were mixed with each LCM at 4000 RPM for intervals of 10 and $30 \mathrm{~min}$.

A high shear multimixer was used to simulate the high shear that the drilling fluids and LCM would be subjected to in the field. This multimixer used could simulate the 
mixing tank in the field and the bit nozzles' shearing effects. The multimixer had six nozzles to produce the required force to shear the materials and the fluids.

\subsubsection{LCM Evaluation in Terms of Plugging Efficiency}

LCM plugging performance analysis studied the ability of the material to plug, or bridge, the simulated fracture width. A key challenge of testing LCM plugging efficiency is the lack of industry standards for defining LCM testing methods and specifications and for interpreting the results [21]. The major service and operator companies use a piece of equipment called a permeability plugging apparatus (PPA) to evaluate LCM properties and plugging efficiency. To simulate the fractures, a circular hole was opened (drilled) in the slotted discs with the different fracture diameters.

\subsubsection{LCM Evaluation Testing Protocol}

The testing protocol for this study was to examine the plugging ability of the LCMs before and after exposure to fluids to understand the size degradation effect on the materials' plugging efficiency and their ability to bridge and plug fractures downhole. The research methodology started with preparing two different fluids and material mixtures. The drilling fluid used in this study was only clay-based fluids, and the first mixture was not subjected to shear. The LCM and the fluid (clay system) were mixed for one minute with a spatula to minimize forces on the particles. This mixture of the clay-based fluid was used to investigate the material's behavior without a size degradation effect. The second mixture received a high shear of $4000 \mathrm{RPM}$ for up to $30 \mathrm{~min}$, as per the size degradation procedure. These two mixtures were tested at test conditions of 500 psi pressure and ambient temperature. The LCM plugging performance testing investigated the fracture plugging capability with and without the size degradation effect to understand its impact on the different LCM types.

The objective of the evaluation protocol was to determine the maximum fracture diameter that could be plugged using both the "no shearing" and the "30 min shearing" samples of each LCM. For all of the LCMs, the largest fracture diameter tested was 6 $\mathrm{mm}$, after which were tested smaller diameters with an increment of $0.5 \mathrm{~mm}$, simulating smaller fractures. The objective was to compare each LCM with itself in terms of the effect of shearing and mixing. The change of the maximum fracture sized plugged with and without shearing for each LCM is reported, which led to the development of the particle size selection guidelines.

\section{Results and Discussion}

\subsection{PSD Results}

\subsubsection{Dry PSD}

The materials' dry phase PSD results and analysis were conducted on the three different granular materials of LCMs (walnut, graphite, and marble). The five particle size distributions (Ds) and the span (the difference between $\mathrm{D}_{90}$ and $\mathrm{D}_{10}$ divided by $\mathrm{D}_{50}$ ) of all LCMs are shown in Table 4, and their cumulative distributions are plotted in Figure 1. Walnut showed much larger particle sizes than graphite and marble, with a median particle size of $2060 \mu \mathrm{m}$, which is around 4 times larger than the median particle sizes of graphite and marble particles ( $445 \mu \mathrm{m}$ and $545 \mu \mathrm{m}$, respectively). Furthermore, graphite showed the largest span of 1.31, indicating a much wider particle size distribution than walnut and marble ( 0.75 and 0.78 , respectively).

Table 4. Dry cumulative distributions values for all granular materials.

\begin{tabular}{ccccccc}
\hline Material & $\mathbf{D}_{\mathbf{1 0}}(\boldsymbol{\mu m})$ & $\mathbf{D}_{\mathbf{2 5}}(\boldsymbol{\mu m})$ & $\mathbf{D}_{\mathbf{5 0}}(\boldsymbol{\mu m})$ & $\mathbf{D}_{\mathbf{7 5}}(\boldsymbol{\mu m})$ & $\mathbf{D}_{\mathbf{9 0}}(\mu \mathrm{m})$ & Span \\
\hline Walnut & 1463 & 1665 & 2060 & 2578 & 3014 & 0.75 \\
Graphite & 189 & 306 & 445 & 593 & 774 & 1.31 \\
Marble & 352 & 442 & 535 & 662 & 770 & 0.78 \\
\hline
\end{tabular}




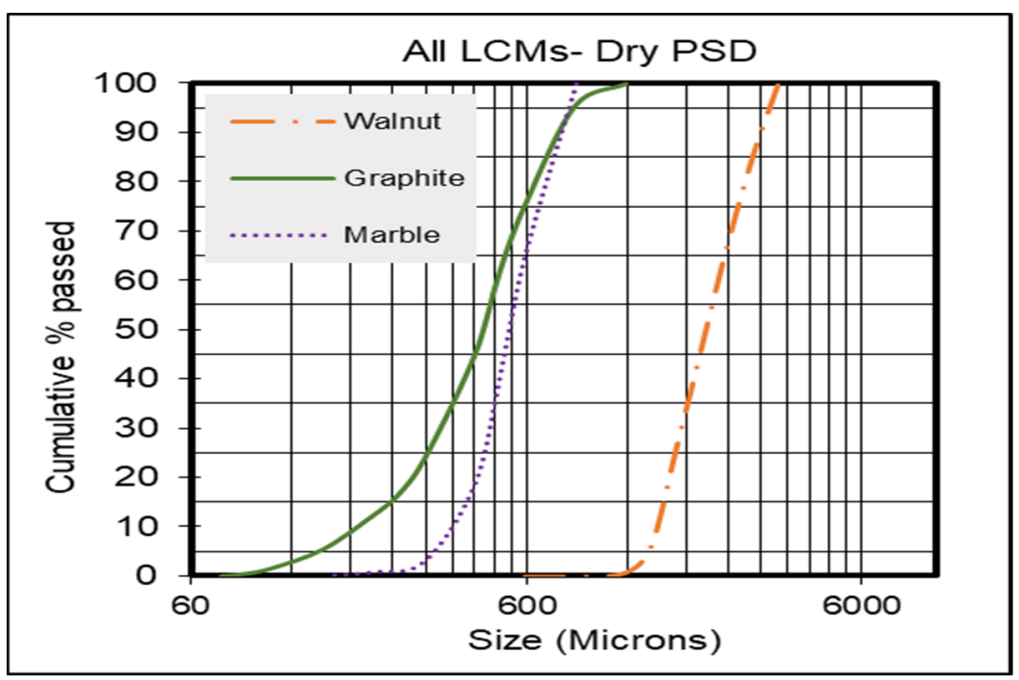

Figure 1. Dry PSD for walnut, graphite, and marble.

\subsubsection{Walnut PSD}

As noted earlier in this study, walnut is a highly rigid material that has been used in drilling fluids for decades. The analysis conducted on the walnut showed that the particle size range of the dry phase was from 3360 to $595 \mu \mathrm{m}$. As shown in Figure 2, the overall performance of walnut with different carrier fluid systems showed that walnut performed with a very minimal size reduction in all fluid systems. Thus, the selection of the fluid type was not a critical issue that would influence the size degradation behavior of walnut.

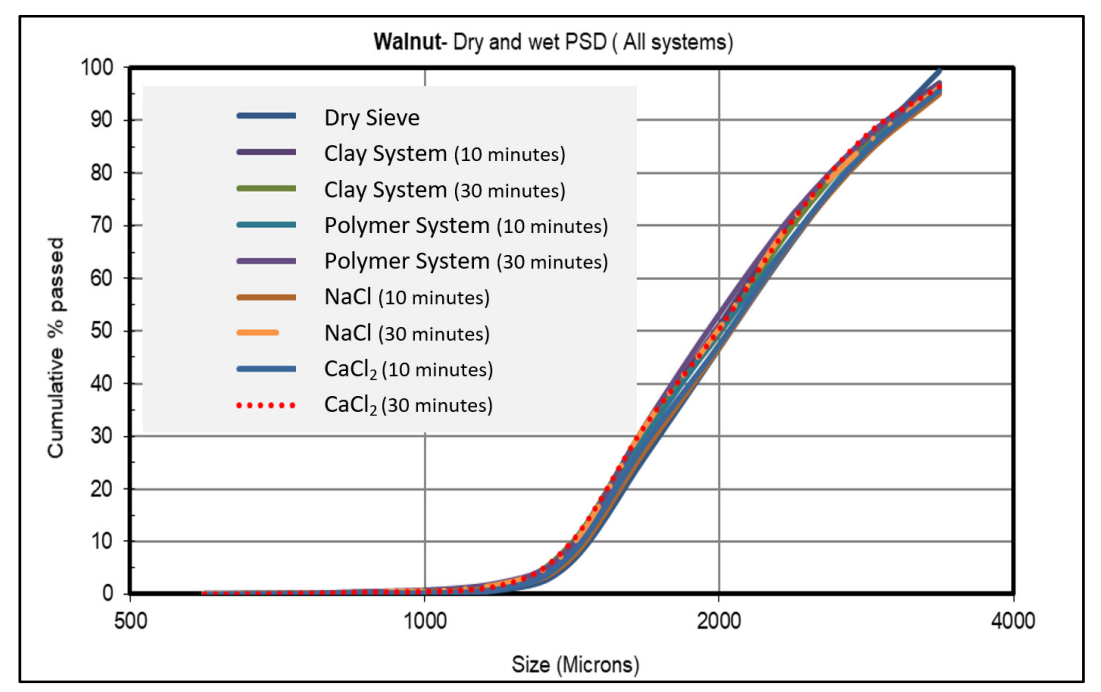

Figure 2. Dry and wet PSD of walnut in the four carrier fluid systems with 10 and $30 \mathrm{~min}$ shearing intervals.

In Tables 5-7, a negative sign in the size degradation results represents the percentage of size reduction, and a positive sign represents the percentage of size expansion. Equation (1) was used to determine the average size degradation for each LCM with the different fluid systems.

$$
\text { Average size degradation }(\%)=\frac{\mathrm{D}_{50}(\text { dry })-\mathrm{D}_{50}(\text { wet })}{\mathrm{D}_{50}(\text { dry })} \times 100
$$


Table 5. Walnut size degradation (30 min shearing only).

\begin{tabular}{cc}
\hline Drilling Fluid Systems & Average Size Degradation (\%) \\
\hline Clay base & $-4 \%$ \\
Polymer base & $-3 \%$ \\
Sodium Chloride $(\mathrm{NaCl})$ systems & $-5 \%$ \\
Calcium Chloride $\left(\mathrm{CaCl}_{2}\right)$ systems & $-4 \%$ \\
Average & $-4 \%$ \\
\hline
\end{tabular}

Table 6. Graphite size degradation (30 min shearing only).

\begin{tabular}{cc}
\hline Drilling Fluid Systems & Average Size Degradation (\%) \\
\hline Clay base & $0 \%$ \\
\hline Polymer base & $1 \%$ \\
\hline Sodium Chloride $(\mathrm{NaCl})$ systems & $3 \%$ \\
\hline Calcium Chloride $\left(\mathrm{CaCl}_{2}\right)$ systems & $0 \%$ \\
\hline Average & $1 \%$ \\
\hline
\end{tabular}

Table 7. Marble size degradation ( 30 min shearing only).

\begin{tabular}{cc}
\hline Drilling Fluid Systems & Average Size Degradation (\%) \\
\hline Clay base & $-44 \%$ \\
\hline Polymer base & $-32 \%$ \\
\hline Sodium Chloride $(\mathrm{NaCl})$ systems & $-29 \%$ \\
\hline Calcium Chloride $\left(\mathrm{CaCl}_{2}\right)$ Systems & $-26 \%$ \\
\hline Average & $-33 \%$ \\
\hline
\end{tabular}

Table 5 shows the detailed results of size degradation for walnut in all the tested carrier fluids. It was observed that the percentage average size degradation of walnut was a $4 \%$ reduction in the overall particle size distribution in all fluid systems. The $4 \%$ reduction is considered negligible for drilling fluid applications.

\subsubsection{Graphite PSD}

Graphite is a resilient, dual composition, and carbon-based material. It has a unique characteristic that imparts resiliency and the ability to recover its initial size and volume up to $120 \%$ [22]. During the dry particle size distribution experiment on graphite, the analysis showed that the particle size ranged from 1190 to $74 \mu \mathrm{m}$. The overall performance of graphite with the different carrier fluid systems showed that the material performed with a very minimal size reduction with all carrier fluid systems and that the carrier fluid types did not affect the graphite size degradation performance, as shown in Figure 3. 


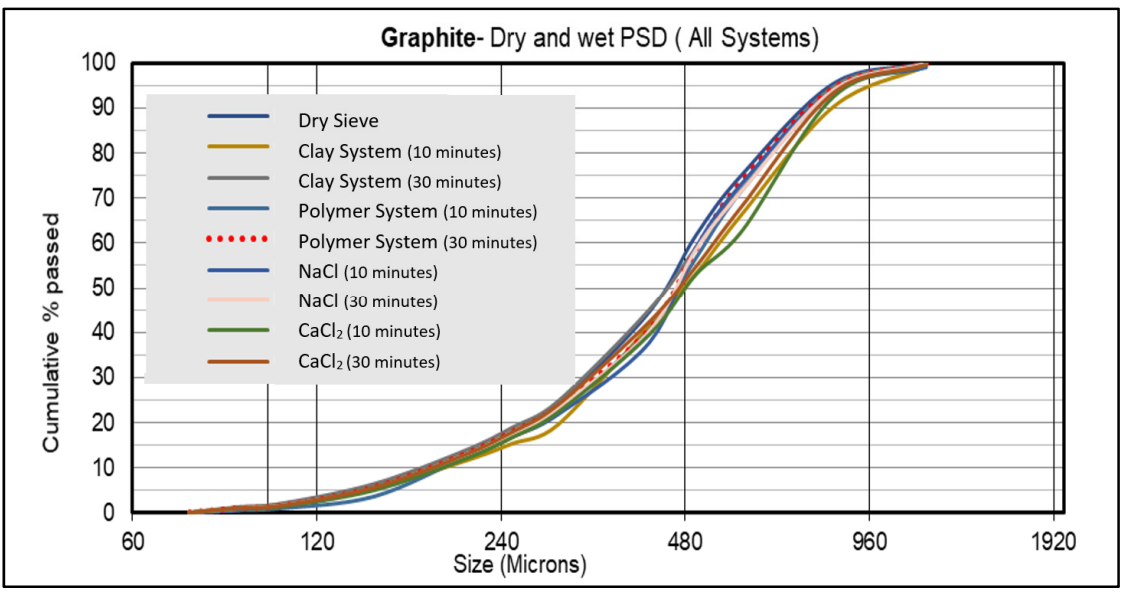

Figure 3. Dry and wet PSD of graphite in the four carrier fluid systems with 10 and 30 min shearing intervals.

The size degradation analysis of graphite confirmed that the material did not experience any size reduction but showed a slight size expansion. The detailed size degradation results are shown in Table 6. The overall percentage size degradation of graphite in all fluids was reported at an average of $1 \%$ size increase. This increase in size resulted from the high resiliency of graphite, which confers the ability to recover more than its original size.

\subsubsection{Marble PSD}

Marble dry sieves testing result showed a range of particle sizes from 841 to $149 \mu \mathrm{m}$. The overall performance of marble with the different carrier fluid systems showed that the material experienced a greater size reduction in all the four carrier systems as compared with the LCM tested in this study. The comparative analysis showed that marble had a better performance with a smaller percentage size degradation in all polymer systems (with and without salt) than in the clay system, as shown in Figure 4.

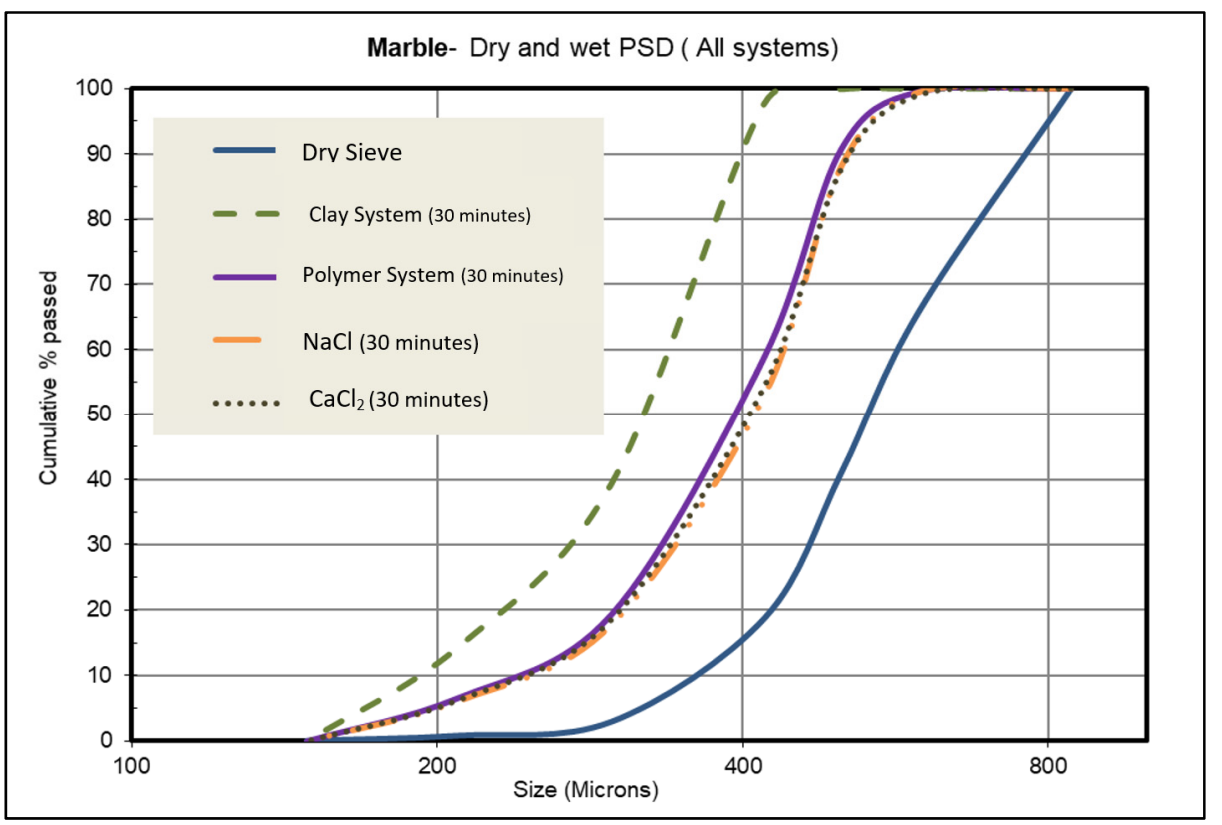

Figure 4. Dry and wet PSD of marble in the four carrier fluid systems with 30 min shearing intervals.

The marble size degradation analysis revealed that marble showed a significant percentage of size degradation, which varied with the fluid system used. The average percentage size degradation concept of the four fluid systems should not be used with 
marble since some fluids proved to behave differently. Based on the material performance with the four fluid systems, the fluid systems can be divided into two groups: a clay systems group and an all-polymer systems group. The percentage average size of degradation in the clay system was reported at a $44 \%$ reduction in overall size (dry sample size). Meanwhile, the average percentage size degradation in the polymer systems (with and without salt) was a $29 \%$ reduction in size, as shown in Table 7 .

\subsection{Plugging Performance}

\subsubsection{Walnut Plugging Performance}

Walnut was able to seal a maximum $2.0 \mathrm{~mm}$ fracture width in either the simulated situation of no shearing or the situation with a high shearing effect. Thus, the material's plugging efficiency was not materially affected by the minimum size degradation seen during testing. The fluid loss during testing with no shearing and with high shearing was 15 and $19 \mathrm{~mL}$, respectively. The fluid loss volume increase was because of the size degradation and the absence of some of the larger particles, which adversely affected the bridging mechanism, as shown in Figure 5.

\begin{tabular}{|c|c|c|c|c|c|}
\hline \multicolumn{2}{|c|}{ No Shearing } & \multicolumn{3}{|c|}{ 30-Minutes Shearing } \\
\hline $\begin{array}{c}\text { Size of } \\
\text { (slotted), } \\
\mathbf{m m}\end{array}$ & $\begin{array}{c}\text { Fluid } \\
\text { Loss, } \\
\mathbf{c m}^{3}\end{array}$ & Plugging Photo & $\begin{array}{c}\text { Size of } \\
\text { Fracture } \\
\text { (slotted), } \\
\mathbf{m m}\end{array}$ & $\begin{array}{c}\text { Fluid } \\
\text { Loss, } \\
\mathbf{c m}^{3}\end{array}$ & Plugging Photo \\
\hline $\mathbf{2 . 0}$ & 15 & $\mathbf{2 . 0}$ & 19 & \\
\hline
\end{tabular}

Figure 5. Walnut maximum plugged fracture diameter before and after shearing force.

The original walnut dry phase $\mathrm{D}_{50}$ was $2060 \mu \mathrm{m}$, while the $\mathrm{D}_{50}$ after degradation was $1972 \mu \mathrm{m}$. Therefore, the newly developed particle size selection criterion is based on the original $D_{50}$ of the dry phase given in Equation (2). It states that the median particle size of walnut over the fracture width size must be equal to or greater than 1.0 to plug the fracture.

$$
\frac{\mathrm{D}_{50}}{\text { Fracture width size }} \geq 1.0
$$

\subsubsection{Graphite Plugging Performance}

While studying the plugging efficiency of graphite, it was observed that the material was able to plug a maximum fracture width of $0.5 \mathrm{~mm}$ and maintained the same fluid loss volume both for situations of shearing and without shearing. The size degradation did not affect the material performance in plugging the fracture width size because the graphite did not experience any fluid loss, as shown in Figure 6. 


\begin{tabular}{|c|c|c|c|c|c|}
\hline \multicolumn{3}{|c|}{ No Shearing } & \multicolumn{2}{|c|}{ 30-Minutes Shearing } \\
\hline $\begin{array}{c}\text { Size of } \\
\text { Fracture } \\
\text { (slotted), } \\
\text { mm }\end{array}$ & $\begin{array}{c}\text { Fluid } \\
\text { Loss, } \\
\mathbf{c m}^{3}\end{array}$ & Plugging Photo & $\begin{array}{c}\text { Size of } \\
\text { Fracture } \\
\text { (slotted), } \\
\mathbf{m m}\end{array}$ & $\begin{array}{c}\text { Fluid } \\
\text { Loss, } \\
\mathbf{c m}^{3}\end{array}$ & $\begin{array}{c}\text { Plugging Photo } \\
0.5\end{array}$ \\
\hline & 12 & 0.5 & 12 & \\
\hline
\end{tabular}

Figure 6. Graphite maximum plugged fracture diameter before and after shearing force.

The size degradation of graphite was recorded at only $1 \%$, and the $\mathrm{D}_{50}$ values before and after degradation were 445 and $448 \mu \mathrm{m}$, respectively. Therefore, the newly developed particle size selection criterion is given below in Equation (3). It states that the median particle size of graphite over the fracture width size must be equal to or greater than 0.9 to plug the fracture.

$$
\frac{\mathrm{D}_{50}}{\text { Fracture width size }} \geq 0.9
$$

\subsubsection{Marble Plugging Performance}

The marble mixture with no shearing was able to plug the simulated fracture maximum width of $1.5 \mathrm{~mm}$, while the sheared mixture with size degradation was able to plug a smaller fracture width with a maximum size of $1.0 \mathrm{~mm}$, as shown in Figure 7. The plugged fracture width size with shearing was 33\% less than without shearing $(1.5 \mathrm{~mm}$ and $1.0 \mathrm{~mm}$, respectively). The $\mathrm{D}_{50}$ of the marble before and after degradation was 535 and $322 \mu \mathrm{m}$, respectively. The newly developed particle size selection criterion for marble is shown in Equation (4). It states that the median particle size of marble over the fracture width size must be equal to or greater than 0.5 to plug the fracture.

$\frac{\mathrm{D}_{50}}{\text { Fracture width size }} \geq 0.5$

\begin{tabular}{|c|c|c|c|c|c|}
\hline \multicolumn{3}{|c|}{ No Shearing } & \multicolumn{3}{|c|}{ 30-Minutes Shearing } \\
\hline $\begin{array}{c}\text { Size of } \\
\text { Fracture } \\
\text { (slotted), } \\
\text { mm }\end{array}$ & $\begin{array}{c}\text { Fluid } \\
\text { Loss, } \\
\mathrm{cm}^{3}\end{array}$ & Plugging Photo & $\begin{array}{c}\text { Size of } \\
\text { Fracture } \\
\text { (slotted), } \\
\text { mm }\end{array}$ & $\begin{array}{c}\text { Fluid } \\
\text { Loss, } \\
\mathrm{cm}^{3}\end{array}$ & Plugging Photo \\
\hline 1.5 & 19 & & 1.0 & 21 & \\
\hline
\end{tabular}

Figure 7. Marble maximum plugged fracture diameter before and after shearing force. 


\section{Conclusions}

There is a variety of information and analysis that must be assimilated and understood to plan the best lost circulation management process. Lost circulation management with due diligence is a process of evaluating the material, fluids, and the many other factors involved. This study developed a strategy and a process for new lost circulation management to introduce new LCM particle size selection criteria to enhance the plugging efficiency of three granular LCMs (walnut, graphite, and marble). Additionally, this study identified the limitations of material effectiveness that are imposed by various external factors by investigating the size degradation encountered for the three LCMs with four different carrier fluid systems.

The following conclusions are based on the work presented in this study.

- The effect of the carrier fluid type (water-bentonite mix, water-polymer mix, polymersalt system using $\mathrm{NaCl}$ salt, or polymer-salt system using $\mathrm{CaCl}_{2}$ salt) was proven to be significant on marble particles size degradation.

- Marble showed a significant size degradation with clay systems, whereas it was less impacted by either of the polymer systems used in the study.

- Walnut and graphite were not affected by the carrier fluids and showed consistent size degradation performance with all fluids.

- The LCM plugging performance testing developed in this study simulated the plugging of different fracture widths using the three LCM-either with or without the size degradation effect- to understand their impact on the different LCM types.

- Only marble showed 33\% less efficiency of plugging the fracture width after shearing compared with plugging the width without shearing, emphasizing the effect of particle size degradation.

- A new criterion for LCM particle size selection was developed for each of the three granular LCMs to enhance their plugging efficiency.

Author Contributions: Conceptualization, S.A.A. (Saleh A. Alhaidari); methodology, S.A.A. (Saleh A. Alhaidari); validation, S.A.A. (Saleh A. Alhaidari) and S.A.A. (Sulaiman A. Alarifi); formal analysis, S.A.A. (Saleh A. Alhaidari); data curation, S.A.A. (Saleh A. Alhaidari) and S.A.A. (Sulaiman A. Alarifi); writing-original draft preparation, S.A.A. (Saleh A. Alhaidari) and S.A.A. (Sulaiman A. Alarifi); writing-review and editing, S.A.A. (Sulaiman A. Alarifi); supervision, S.A.A. (Saleh A. Alhaidari). All authors have read and agreed to the published version of the manuscript.

Funding: This research received no external funding.

Institutional Review Board Statement: Not applicable.

Informed Consent Statement: Not applicable.

Data Availability Statement: Not applicable.

Acknowledgments: The authors of this article acknowledge and highly appreciate Saudi Aramco and King Fahd University of Petroleum \& Minerals (KFUPM) for their support in publishing this work.

Conflicts of Interest: The authors declare no conflict of interest.

\section{Nomenclature}

$\mathrm{D}_{10} \quad$ Maximum particle size of $10 \%$ of the particles, $\mu \mathrm{m}$

$\mathrm{D}_{25} \quad$ Maximum particle size of $25 \%$ of the particles, $\mu \mathrm{m}$

$\mathrm{D}_{50} \quad$ Median particle size, $\mu \mathrm{m}$

$D_{75}$ Maximum particle size of $75 \%$ of the particles, $\mu \mathrm{m}$

$\mathrm{D}_{90}$ Maximum particle size of $90 \%$ of the particles, $\mu \mathrm{m}$

LCM Lost circulation material

PSD Particle size distribution

RPM Revolutions per minute 


\section{References}

1. Murtaza, M.; Alarifi, S.A.; Kamal, M.S.; Onaizi, S.A.; Al-Ajmi, M.; Mahmoud, M. Experimental Investigation of the Rheological Behavior of an Oil-Based Drilling Fluid with Rheology Modifier and Oil Wetter Additives. Molecules 2021, 26, 4877. [CrossRef] [PubMed]

2. Caenn, R.; Chillingar, G.V. Drilling fluids: State of the art. J. Pet. Sci. Eng. 1996, 14, 221-230. [CrossRef]

3. White, R.J. Lost-Circulation Materials and Their Evaluation. In Proceedings of the Drilling and Production Practice, New York, NY, USA, 1 January 1956. API-56-352.

4. Cook, J.; Growcock, F.; Guo, Q.; Hodder, M.; van Oort, E. Stabilizing the Wellbore to Prevent Lost Circulation. Oilfield Rev. 2011, 23, 26-35.

5. Gaurina-Međimurec, N.; Pašić, B.; Mijić, P.; Medved, I. Drilling Fluid and Cement Slurry Design for Naturally Fractured Reservoirs. Appl. Sci. 2021, 11, 767. [CrossRef]

6. Miller, M.; Scorsone, J.; Whitfill, D.L.; McDonald, M.; Miller, N. The Development of a Geopolymer-Based Pill as an Engineered Solution to Lost Circulation. In Proceedings of the SPE Annual Technical Conference and Exhibition, Society of Petroleum Engineers (SPE), New Orleans, LA, USA, 30 September-2 October 2013.

7. Alsaba, M.; Nygaard, R.; Hareland, G.; Contreras, O. Review of Lost Circulation Materials and Treatments with an Updated Classification. In Proceedings of the AADE Fluids Technical Conference and Exhibition, Houston, TX, USA, 15-16 April 2014.

8. Gaurina-Međimurec, N.; Pašić, B. Lost Circulation. In Risk Analysis for Prevention of Hazardous Situations in Petroleum and Natural Gas Engineering, 1st ed.; Matanović, D., Gaurina-Međimurec, N., Simon, K., Eds.; IGI Global: Hershey, PA, USA, 2014; pp. 73-95.

9. Vivas, C.; Salehi, S. Wellbore Strengthening for Geothermal Applications: Experimental Study of Thermal Degradation of LCM to Address Wellbore Tensile Failure. In Proceedings of the 55th U.S. Rock Mechanics/Geomechanics Symposium, Virtual, 22 June 2021.

10. Valsecchi, P. On the Shear Degradation of Lost Circulation Materials. In Proceedings of the SPE/IADC Drilling Conference and Exhibition, Amsterdam, The Netherlands, 5-7 March 2013. SPE-163512-MS. [CrossRef]

11. Grant, P.; Lassus, L.; Savari, S.; Whitfill, D.L. Size Degradation Studies of Lost Circulation Materials in a Flow Loop. In Proceedings of the IADC/SPE Drilling Conference, Fort Worth, TX, USA, 1-3 March 2016. SPE-178774-MS. [CrossRef]

12. Scott, P.D.; Beardmore, D.H.; Wade, Z.L.; Evans, E.; Franks, K.D. Size Degradation of Granular Lost Circulation Materials. In Proceedings of the IADC/SPE Drilling Conference, San Diego, CA, USA, 6-8 March 2012. SPE-151227-MZ. [CrossRef]

13. Whitfill, D.L.; Hemphill, T. All Lost-Circulation Materials and Systems Are Not Created Equal. In Proceedings of the SPE Annual Technical Conference, Denver, CO, USA, 5-8 October 2003. SPE-84319-MS. [CrossRef]

14. Alhaidari, S.A.; Eustes, A.W. Lost Circulation Management: New Engineering Approaches and Techniques for Better Bridging and Sealing the Fracture. Ph.D. Thesis, Colorado School of Mines, Golden, CO, USA, March 2020.

15. Abrams, A. Mud Design to Minimize Rock Impairment Due to Particle Invasion. J. Pet. Technol. 1977, 29, 586-592, SPE-5713-P. [CrossRef]

16. Smith, P.; Browne, S.V.; Heinz, T.J.; Wise, W.V. Drilling Fluid Design to Prevent Formation Damage in High Permeability Quartz Arenite Sandstones. In Proceedings of the SPE Annual Technical Conference, Denver, CO, USA, 6-9 October 1996. SPE-36430-MS. [CrossRef]

17. Vickers, S.; Cowie, M.; Jones, T.; Twynam, A.J. A New Methodology that Surpasses Current Bridging Theories to Efficiently Seal a Varied Pore Throat Distribution as Found in Natural Reservoir Formations. In Proceedings of the AADE Fluids Technical Conference, Houston, TX, USA, 11-12 April 2006. AADE-06-DF-HO-16.

18. Whitfill, D. Lost Circulation Material Selection, Particle Size Distribution and Fracture Modeling with Fracture Simulation Software. In Proceedings of the IADC/SPE Asia Pacific Drilling Technology Conference, Jakarta, Indonesia, 25-27 August 2008. SPE-115039-MS. [CrossRef]

19. Howard, G.C.; Scott, P.P., Jr. An Analysis and the Control of Lost Circulation. J. Pet. Technol. 1951, 3, 171-182, SPE-951171-G. [CrossRef]

20. Savari, S.; Kumar, A.; Whitfill, D.L.; Jamison, D.E. Improved Lost Circulation Treatment Design and Testing Techniques Minimize Formation Damage. In Proceedings of the SPE European Formation Damage Conference, Noordwijk, The Netherlands, 7-10 June 2011. SPE-143603-MS. [CrossRef]

21. Amer, A.; Hale, A.; Al Haidari, S. Addressing the Challenges of Lost Circulation Using Novel Chemistries, Test Equipment and Data Science Tools. In Proceedings of the AADE National Technical Conference, Denver, CO, USA, 9-10 April 2019. AADE-19-NTCE-056.

22. Lavrov, A. Lost Circulation: Mechanisms and Solutions; Gulf Professional Publishing: Cambridge, MA, USA, 2016. [CrossRef] 